\title{
Disaster Surveillance: Perspectives from Federal, State, and Local levels
}

\author{
Eric V. Bakota ${ }^{\star 1}$, David Atrubin ${ }^{2}$, Michael Coletta ${ }^{3}$ and Aaron Kite-Powell ${ }^{3}$ \\ ${ }^{1}$ Health Department, Harris County Public Health, Houston, TX, USA; ${ }^{2}$ Florida Department of Health, Tallahassee, FL, USA; ${ }^{3} \mathrm{CDC}$, \\ Atlanta, GA, USA
}

\section{Objective}

In this panel, attendees will learn about how disaster surveillance was conducted in response to Hurricanes Irma and Harvey, as well as the role of $\mathrm{CDC}$ at the federal level in supporting local response efforts. By hearing and discussing the challenges faced and solutions identified, attendees will be better able to respond in the event of a low-frequency/high-consequence disaster occurring within their jurisdiction.

\section{Introduction}

In this panel, the presenters will discuss their perspective in responding to Hurricanes Harvey and Irma. Hurricane Harvey made landfall on August 25th and over the course of 4 days dropped approximately 27 trillion gallons of water on Texas and Louisiana. ${ }^{1}$ The flooding that ensued was unprecedented and forced over 13,000 people into shelters. ${ }^{2}$ These individuals needed to have their basic needs -food, shelter, clothing, sanitation- met as well as their physical and mental health needs. The George R Brown Conference Center (GRB) and NRG Stadium Center were set up as mega-shelters to house shelterees. Hurricane Irma made landfall on September 10th in the Florida Keys as a Category 4 Hurricane. The Hurricane caused 72 deaths ${ }^{3}$ and forced thousands of people into shelters. ${ }^{4}$ These weather events created novel challenges for local response efforts. Decision makers needed timely and actionable data, including surveillance data.

\section{Keywords}

disaster epidemiology; informatics; preparedness

\section{References}

1. Sanchez R, Yan H, Simon D. Harvey aftermath: Houston 'open for business'; other cities suffering. CNN. 2017 Sep 1.

2. Sullivan K, Hernandez A, Fahrenthold D. Harvey leaving record rainfall, at least 22 deaths behind in Houston. Chicago Tribune. 2017 Aug 29.

3. Impact of Hurricane Irma. Boston Globe. Accessed 2017 Oct 10. https://www.bostonglobe.com/news/bigpicture/2017/09/11/impacthurricane-irma/W6WBN9K21Xd4gPmtu26auN/story.html

4. Smith A. After Hurricane Irma, Many Ask: How Safe Are Shelters? Tampa Bay Times. 2017 September 21.

\section{*Eric V. Bakota}

E-mail: eric.bakota@gmail.com 